УДК 616.001; 616.006; 616.03

\title{
СЕСТРИНСКИЙ УХОД В ПРОЦЕССЕ РЕАБИЛИТАЦИИ ПАЦИЕНТОВ ПОСЛЕ НЕЙРОХИРУРГИЧЕСКИХ ОПЕРАЦИЙ НА ГОЛОВНОМ МОЗГЕ
}

Научный руководитель: Табатадзе Наталия Владиславовна зам. директора по УМР

ГБПОУ «Новороссийский медицинский колледж» Научный руководитель: Ольхова Ольга Валентиновна

преподаватель первой категории

ГБПОУ «Новороссийский медицинский колледж»

Яковенко Елена Николаевна

к. филол. н., ст. преподаватель, преподаватель высшей категории ФГБОУ ВО «ГМУ им. адм. Ф.Ф. Ушакова», г. Новороссийск Яковенко Никита Алексеевич студент IVкурса

ГБПОУ «Новороссийский медицинский колледж»

Аннотация: статья посвящена проблемам, связанным с медицинской практикой хирургического вмешательства в область головного мозга и роли сестринского ухода в процессе реабилитации пациентов после нейрохирургических операций на головном мозге, так как весь основной уход за больным осуществляет средний медицинский персонал.

Ключевые слова: нейрохирургия, профилактика, инфаркт, инсульт, пациенты, статистические данные, брошюра, анкета.

\section{NURSING CARE IN THE PROCESS OF REHABILITATION OF PATIENTS AFTER NEUROSURGICAL OPERATIONS ON THE BRAIN}

\section{Tabatadze Natalia Vladislavovna Olkhova Olga Valentinovna Yakovenko Elena Nikolaevna Yakovenko Nikita Alekseevich}

Abstract: the article is devoted to the problems related to the medical practice of surgical intervention in the brain area and the role of nursing care in the 


\section{ЦИФРОВИЗАЦИЯ КАК НОВАЯ ПАРАДИГМА РАЗВИТИЯ: ВЫЗОВЫ, ВОЗМОЖНОСТИ И ПЕРСПЕКТИВЫ}

process of rehabilitation of patients after neurosurgical operations on the brain, since all the basic care of the patient is carried out by secondary medical personnel.

Key words: neurosurgery, prevention, heart attack, stroke, patients, statistical data, brochure, questionnaire.

В медицинской практике хирургическое вмешательство в область головного мозга считается одним из наиболее опасных видов. Опухоли головного мозга составляют до $6 \%$ всех новообразований в организме человека. Частота их встречаемости колеблется от 10 до 15 случаев на 100 тыс. человек.

Традиционно к церебральным опухолям относят все интракраниальные новообразования - опухоли церебральной ткани и оболочек, образования черепных нервов, сосудистые опухоли, новообразования лимфатической ткани и железистых структур (гипофиза и шишковидной железы). В связи с этим опухоли головного мозга делят на внутримозговые и внемозговые. К последним относят новообразования церебральных оболочек и их сосудистых сплетений [6, с.14-15].

Сердечно-сосудистые заболевания долгое время лидируют в рейтинге причин смертности. По оценкам Всемирной организации здравоохранения в 2016 году от болезней сердца умерло 17,9 миллионов человек. Причина 85\% всех этих смертей - инфаркты и инсульты. По данным Фонда по борьбе с инсультом (ОРБИ) в России каждые полторы минуты ктото переносит инсульт [1, с.98].

Согласно статистике, приводимой American Stroke Association, 10\% людей, переживших инсульт, восстанавливаются полностью, $25 \%$ - с незначительными нарушениями, $40 \%$ - получают средние или тяжелые нарушения, требующие особого ухода, $10 \%$ - нуждаются в переводе в специализированное учреждение долговременного ухода, $15 \%$ - умирают вскоре после инсульта [11, с. 102].

По данным ВОЗ, ежегодно в мире регистрируется 100-300 случаев мозгового инсульта (МИ) на каждые 100 тыс. населения. В России этот показатель составляет 250-300 случаев на 100 тыс. населения [5, с.124-125].

Таким образом, любое хирургическое вмешательство в область головного мозга всегда сопряжено с различными рисками возникновения осложнений и прочих побочных эффектов. 


\section{ЦИФРОВИЗАЦИЯ КАК НОВАЯ ПАРАДИГМА РАЗВИТИЯ: ВЫЗОВЫ, ВОЗМОЖНОСТИ И ПЕРСПЕКТИВЫ}

Нервная ткань является сложнейшей живой структурой известной человечеству. Также она крайне хрупка и легко подвержена к воздействию внешних и внутренних факторов[4, с.342].

Вне зависимости от причины возникновения необходимости нейрохирургического вмешательства, любая подобная травма, патология и, собственно, само хирургическое воздействие на головной мозг почти гарантировано повлекут за собой ряд крайне тяжёлых последствий, например, параличи конечностей (частичные, полные) с одной или двух сторон, утрата зрения, слуха, способности к речи, глотанию, дыханию и т. д.

Для их минимизации требуется грамотный подход к организации процесса реабилитации таких пациентов.

Актуальность темы нашего исследования заключается в том, что после хирургического лечения пациентов на головном мозге, процесс реабилитации занимает большой промежуток времени, и важную роль на раннем этапе восстановления играет средний медицинский персонал. Как правило, пациент сталкивается с рядом осложнений, которые выступают факторами, не позволяющими ему самостоятельно справляться с повседневными задачами, порой полностью нарушая все жизненные потребности пациента.

Весь основной уход за больным осуществляет средний медицинский персонал, который не только помогает пациенту справляться с потребностями, но также играет важную роль в процессе исполнения всех восстановительных мероприятий: профилактике пролежней, проведении дыхательной гимнастики, оказании психологической помощи пациенту, проявляет активное участие в процессе восстановления моторики и речи [9, с.178].

Медицинская сестра должна знать правила ухода за пациентами и тем самым грамотно решать возникающие проблемы у пациента в процессе их лечения, тем самым способствуя улучшению качества жизни пациента и предупреждению возможных осложнений [8, с.87-88].

Целью нашего исследования явилось изучение роли сестринского ухода в процессе реабилитации пациентов после нейрохирургических операций на головном мозге на раннем этапе восстановления.

Для достижения поставленных целей нам было необходимо изучить причины нейрохирургических операций, проводимых на головном мозге, их виды и диагностику, методы лечения и возможные осложнения, этапы реабилитации пациентов после перенесенных операций на головном мозге и 


\section{ЦИФРОВИЗАЦИЯ КАК НОВАЯ ПАРАДИГМА РАЗВИТИЯ: ВЫЗОВЫ, ВОЗМОЖНОСТИ И ПЕРСПЕКТИВЫ}

обозначить роль сестринского ухода в процессе их восстановления на раннем послеоперационном периоде.

Исследования проводились на базе одного из ведущих отделений нейрохирургического отделения ГБУЗ «Городская больница №1» г. Новороссийска - нейрохирургического. Оно было создано в 1982 году, а спустя 20 лет преобразовано в межтерриториальный нейрохирургический центр с обслуживанием населения таких городов Краснодарского края как: Новороссийск, Анапа, Крымск, Геленджик, Абинск. В структуре отделения выделены 42 койки, из них 4 - детских, 4 - дневного стационара, 34 койки для взрослых.

С 2010 года отделение оказывает высокотехнологическую помощь больным с геморрагическими и ишемическими инсультами в экстренном и плановом порядке. Успешно проводится лечение пациентов с сосудистой патологией ЦНС. Отделение оснащено специализированным дорогостоящим оборудованием, имеется 64-срезовый компьютерный томограф, ангиограф, навигационная система, нейрохирургические микроскопы, нейроэндоскоп, электронно-оптический преобразователь, нейрохирургический инструментарий.

Ежедневно врачи оказывают медицинскую помощь взрослым и детям. В отделении проводится консервативное лечение черепно-мозговых травм, дегенеративных заболеваний позвоночника на шейном, грудном и поясничном отделах позвоночника II-IV степени. Особое значение придается оперативному лечению травм ЦНС, позвоночника с повреждением спинного мозга, сосудистых патологий и прочим.

Высокий процент удачно проведенных операций объясняется опытом и профессионализмом сотрудников отделения под руководством заведующего Деревцова Александра Андреевича, врача - нейрохирурга 1-ой категории.

Нейрохирургическое отделение оказывает круглосуточную неотложную и экстренную помощь в необходимом диагностическом и лечебном объеме. Плановая госпитализация осуществляется по направлению врача поликлиники.

Для достижения поставленных целей нами были проведены следующие мероприятия: сделан статистический анализ проведенных операций на головном мозге на основе данных НХО ГБУЗ «Городская больница №1» г. Новороссийска; проведен опрос среди пациентов отделения, с целью определения причин необходимости в оперативном вмешательстве и 


\section{ЦИФРОВИЗАЦИЯ КАК НОВАЯ ПАРАДИГМА РАЗВИТИЯ: ВЫЗОВЫ, ВОЗМОЖНОСТИ И ПЕРСПЕКТИВЫ}

возникающих проблем у пациентов в процессе их восстановления, при помощи составленной нами анкеты (рис.1).

Также нами были изучены правила сестринского ухода и составлен план сестринских вмешательств процесса реабилитации пациентов после операции на головном мозге в условиях стационара, сделаны выводы и разработаны методические рекомендации.

Из всего выше сказанного, можно сделать выводы о том, что наиболее распространёнными причинами нейрохирургического вмешательства в область головного мозга являются: травмы нервной системы и их осложнения; опухоли головного мозга, аневризмы сосудов мозга; геморрагические и ишемические инсульты; некоторые последствия воспалительных заболеваний; экстрапирамидные синдромы, эпилепсия, некоторые пороки развития.

Цель радикальных операций состоит в удалении патологических образований: гематом, абсцессов, опухолей, в восстановлении нормальных анатомических взаимоотношений (реконструкций) при травматических переломах черепа, уродствах. В зависимости от срочности операции нейрохирургические вмешательства подразделяются на плановые и экстренные (ургентные). Экстренные операции обычно делаются по жизненным показаниям. Необходимость в безотлагательных операциях возникает при травматических гематомах, при острой окклюзии ликворных путей, при развитии у больного симптомов дислокации мозга и сдавливания его стволовых отделов в большом затылочном или тенториальных отверстиях.

Во время операции или после ее окончания возможны нежелательные последствия, такие как кровотечение (кровоизлияние), иногда единственным его доказательством являются неврологические изменения; боль вследствие травмы тканей; отек вдоль или вокруг разреза, являющийся частью процесса заживления и проходящий спустя 2-4 дня; нарушение функции респираторной системы (угнетение дыхания и расстройство газообмена); проблемы с центральным и регионарным (церебральным) кровообращением; геморрагические осложнения (инфаркт мозга, внутричерепные кровоизлияния); дислокация (смещение) отделов мозга; осложнения гнойновоспалительного характера: внутричерепные (абсцессы, остеомиелит, менингиты, энцефалиты), внечерепные (воспаление легких, к примеру).

Послеоперационная реабилитация включает в себя три периода: острый (длительность от 2 недель до 2,5 месяцев) - выработка реакций защиты на повреждающий фактор; промежуточный (длительность от 6 месяцев до 1 


\section{ЦИФРОВИЗАЦИЯ КАК НОВАЯ ПАРАДИГМА РАЗВИТИЯ: ВЫЗОВЫ, ВОЗМОЖНОСТИ И ПЕРСПЕКТИВЫ}

года) - процесс лизиса и репарации в поврежденных зонах; отдаленный или заключительный (длительность 2-3 года, при осложнениях - вплоть до конца жизни) - завершение дегенерации тканей и восстановления функций. Успешность и длительность реабилитации зависят от характера и тяжести повреждений; от своевременности и качества оказания первой неотложной помощи; от работы специалистов с пациентом во время реабилитации.

Каждый период травматической болезни имеет свои особенности реабилитации.

Ранний период (2-5 суток) - реабилитация сводится к профилактике осложнений со стороны дыхательной и сердечно-сосудистой системы; практикуется профилактика пролежней, делается дыхательная гимнастика и лечение положением; физические нагрузки ограничены, используются пассивные, пассивно-активные упражнения (при сердечно-сосудистых расстройствах, значительной неустойчивости артериального давления, выраженной сердечной недостаточности дыхательные упражнения запрещены). Показан легкий массаж в мышцах для предотвращения отека и снятия спазмов; возможны физиопроцедуры с анальгетиками для предотвращения болевого синдрома, улучшения кровообращения и снятия отеков.

В промежуточный период (5-30 суток) практикуют дыхательную и лечебную гимнастику; применяют лечение положением, локальный и точечный массаж, физиотерапию, термотерапию (парафино-, озокерито- или криотерапию), гидротерапию (вихревые ванны), назначают миорелаксанты (препараты расслабляющие мышцы).

Поздний восстановительный период (с 4-5 недель до 4 месяцев) требует максимальных усилий со стороны пациента, которого постепенно адаптируют к вертикальному положению, подготавливают к вставанию и ходьбе; наряду с лечением, положением и дыхательной гимнастикой увеличивают нагрузку при занятиях ЛФК.

Цель сестринского ухода заключается в организации сестринской помощи, включающей в план своей работы такие мероприятия и так выполняющей их, чтобы, несмотря на болезнь, человек и его семья могли реализовать себя, повысить качество жизни: оценить состояние пациента, определить потребности пациента в уходе, выявить проблемы пациента и их идентифицировать (настоящая или потенциальная проблема), составить план ухода совместно с пациентом для решения его проблем, который состоит из 


\section{ЦИФРОВИЗАЦИЯ КАК НОВАЯ ПАРАДИГМА РАЗВИТИЯ: ВЫЗОВЫ, ВОЗМОЖНОСТИ И ПЕРСПЕКТИВЫ}

индивидуальности, реалистичности, измеряемости и конкретности сроков достижения; провести сестринское вмешательство, предназначенное для достижения цели совместно с другими специалистами.

Исходя из проведенного нами статистического анализа, можно подвести некоторые итоги нашей работы.

По показателям количества пациентов, находящихся на лечении в стационаре, мы отследили динамику заболеваемости. За последние три года наблюдается рост заболеваемости инсультом на 17\%, численность пациентов, поступивших в стационар с онкологическими заболеваниями головного мозга, сохраняет относительную стабильность, колебания составляют около 8\% в большую и меньшую стороны, количество ЧМТ имеет положительную динамику и за последние 3 года количество пациентов, нуждающихся в оперативном нейрохирургическом лечении, сократилось на $18 \%$.

Среди пациентов отделения нами был проведен опрос, с целью определения причин возникновения заболеваний, возникающих проблем у больных в процессе лечения, а также оценки роли и качества сестринского ухода. В процессе анкетирования 26-ти пациентов, 43\% опрошенных составили женщины, 57\% - мужчины. Большая часть пациентов в возрасте от 35 до 60 лет, что составляет 52\%. По результатам опроса пациентов и их родственников было выявлено, что 28,6\% пациентов с диагнозом «инсульт» госпитализированы повторно; пациенты с ЧМТ, находящиеся на стационарном лечении, за хирургическим вмешательством на головном мозге в 100\% случаев обратились впервые; пациенты с опухолевыми заболеваниями, находящиеся на госпитальном лечении, в 12,5\% случаях обратились повторно. У $37,5 \%$ пациентов с опухолевыми заболеваниями головного мозга первичный диагноз был установлен около 3 лет назад, у 12,5\% - около 10 лет назад, а у оставшихся 50\% в течении последнего года.

По результатам опроса пациентов с диагнозом «Инсульт» и их родственников, а также в следствии изучения историй болезней было установлено, что в 57\% случаев причиной развития состояния являлись ранее выявленные заболевания сердечно-сосудистой системы (ишемическая болезнь сердца, артериальная гипертензия, атеросклероз и др.), у 28,5\% - в следствии черепно-мозговой травмы.

Родственники $14,5 \%$ опрошенных считают, что причиной возникновения инсульта послужили сильные стрессы, алкоголь, тяжёлые 


\section{ЦИФРОВИЗАЦИЯ КАК НОВАЯ ПАРАДИГМА РАЗВИТИЯ: ВЫЗОВЫ, ВОЗМОЖНОСТИ И ПЕРСПЕКТИВЫ}

условия труда, переутомления и постоянные физические нагрузки, а также иные факторы.

По результатам опроса пациентов с опухолевыми заболеваниями головного мозга и их родственников было выяснено, что 37,5\% опрошенных считают причиной возникновения опухолей неблагоприятные факторы воздействия окружающей среды, вредные привычки, вредные факторы рабочей среды; 25\% считают наследственную предрасположенность, так как среди их близких родственников также были люди, проходившие лечение или скончавшиеся из-за развития новообразований; в 25\% случаях люди не знают, что послужило причиной возникновения опухолей; в $12,5 \%$ случаях причиной послужили вторичные факторы (прохождение лучевой терапии в связи с лечением иных заболеваний, прохождение иммуносупрессивной терапии, а также наличие ВИЧ-инфекции).

Все пациенты, в процессе лечения, получали своевременную помощь от медицинской сестры. За время нахождения в стационаре 90\% пациентов удовлетворены качеством и полнотой информации предоставляемой медицинской сестрой во время подготовки их к лабораторным и диагностическим исследованиям.

$80,7 \%$ пациентов и их родственников отмечают, что медицинские сёстры проводили с ними беседы по поводу возникающих осложнений по окончанию стационарного лечения после нейрохирургических операций на головном мозге, а также давали им рекомендации по уходу, самоуходу, по принципам прохождения и этапности реабилитации.

Подводя итоги работы, мы сделали вывод о том, что тема нашего исследования является практически значимой.

В настоящее время наиболее распространёнными и достаточно высокими причинами нейрохирургического вмешательства в область головного мозга являются: травмы нервной системы и их осложнения, опухоли головного мозга, аневризмы сосудов мозга, геморрагические и ишемические инсульты, некоторые последствия воспалительных заболеваний, экстрапирамидные синдромы, эпилепсия, некоторые пороки развития и другие причины имеющие тенденции роста.

Практически у каждого пациента, в процессе реабилитации, после нейрохирургической операции на головном мозге, существуют определенные факторы риска, пагубно влияющие на течение болезни. Основные проблемы, которые испытывает пациент во время обострения заболевания - это болевой 


\section{ЦИФРОВИЗАЦИЯ КАК НОВАЯ ПАРАДИГМА РАЗВИТИЯ: ВЫЗОВЫ, ВОЗМОЖНОСТИ И ПЕРСПЕКТИВЫ}

синдром. Медицинская сестра играет большую роль в решении проблем на всех этапах его лечения, принимает участие во всех лечебно-диагностических и реабилитационных мероприятиях. Для этого она должна грамотно осуществлять сестринский уход и наблюдение за пациентом, что поспособствует его быстрейшему выздоровлению, улучшит качества его жизни и предупреждит возникновения осложнений в послеоперационный период.

Наша работа позволит приобрести специальные знания, умения и навыки будущей медицинской сестре в области ухода за пациентами после нейрохирургического вмешательства в область головного мозга, тем самым повысив её профессиональную компетентность.

Разработанная памятка (рис.2) внесет вклад в работу медсестер нейрохирургического профиля.

\begin{tabular}{|c|c|c|}
\hline \multirow[t]{2}{*}{1 Ваш пол: } & \multicolumn{2}{|c|}{ Мужской } \\
\hline & \multicolumn{2}{|c|}{ Женский } \\
\hline \multicolumn{3}{|l|}{2 Ваш возраст: } \\
\hline \multicolumn{3}{|l|}{$\begin{array}{l}3 \text { Какой диагноз и в какой временной промежуток Вам } \\
\text { установили? }\end{array}$} \\
\hline \multicolumn{3}{|l|}{$\begin{array}{l}4 \text { Что, по Вашему мнению, послужило причиной возникновения } \\
\text { заболевания? }\end{array}$} \\
\hline \multicolumn{3}{|l|}{$\begin{array}{l}5 \text { Имеются ли у Вас сопутствующие заболевания нервной, } \\
\text { сердечно-сосудистой или эндокринной системы? Хронические } \\
\text { инфекционные или иные заболевания? (Укажите какие) }\end{array}$} \\
\hline \multicolumn{3}{|l|}{$\begin{array}{l}6 \text { Возникали ли у Вас обострения или осложнения } \\
\text { установленных заболеваний? Как часто? }\end{array}$} \\
\hline \multirow[t]{2}{*}{7 Какая у Вас по счету госпитализация: } & \multicolumn{2}{|c|}{ 1) Первичная } \\
\hline & \multicolumn{2}{|c|}{ 2) Повторная } \\
\hline \multicolumn{3}{|l|}{$\begin{array}{l}8 \text { Какие проблемы со здоровьем Вы испытывали в период } \\
\text { поступления и нахождения на стационарном лечении? }\end{array}$} \\
\hline $\begin{array}{l}9 \text { Во время нахождения на стационарном лечении при } \\
\text { возникновении проблем, связанных с заболеванием, медицинский } \\
\text { персонал отделения оказывал Вам помощь своевременно? }\end{array}$ & Да & Нет \\
\hline $\begin{array}{l}10 \text { Удовлетворены ли Вы качеством и полнотой информации } \\
\text { предоставляемой Вам медицинским персоналом во время } \\
\text { подготовки Вас к лабораторным и диагностическим } \\
\text { исследованиям? }\end{array}$ & Да & Нет \\
\hline $\begin{array}{l}11 \text { Сотрудники отделения проводили с Вами разъяснительные } \\
\text { беседы об основных принципах реабилитации пациентов с Вашим } \\
\text { диагнозом в послеоперационном периоде? }\end{array}$ & Да & Нет \\
\hline
\end{tabular}




\section{ЦИФРОВИЗАЦИЯ КАК НОВАЯ ПАРАДИГМА РАЗВИТИЯ: ВЫЗОВЫ, ВОЗМОЖНОСТИ И ПЕРСПЕКТИВЫ}

\begin{tabular}{|l|l|l|}
\hline $\begin{array}{l}12 \text { Сотрудники отделения проводили с Вами разъяснительные } \\
\text { беседы о наиболее часто возникающих при Вашем диагнозе } \\
\text { осложнениях? }\end{array}$ & Да & Нет \\
\hline 13 Помог ли Вам сестринский уход в процессе лечения? & Да & Нет \\
\hline 14 Оцените работу медицинских сестер по 5-ти балльной шкале: & & \\
\hline $\begin{array}{l}15 \text { На какую тему Вы бы хотели получить рекомендации после } \\
\text { выписки из стационара? }\end{array}$ & & \\
\hline \multicolumn{2}{|c|}{ Благодарим за участие! } & \\
\hline
\end{tabular}

\section{Рис. 1. Анкета}

\section{«Рекомендации по профилактическим мерам для выявления и оказания помощи людям с первыми признаками инсульта»}

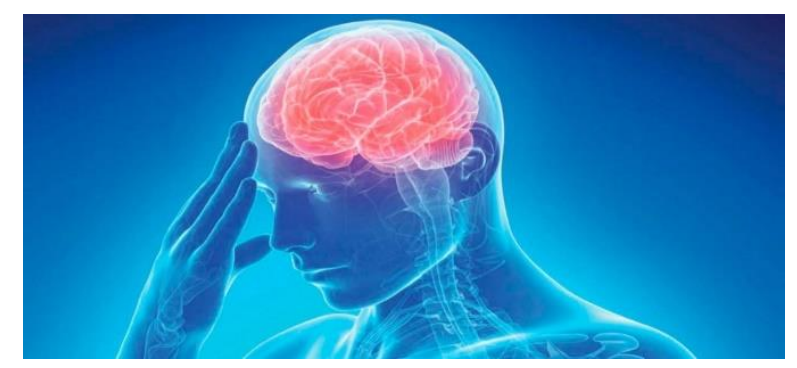

Инсульт - нарушение кровоснабжения отдельных участков головного мозга. Приводит к необратимым их поражениям. Инсульт может быть ишемическим - когда ткани лишаются кислорода на длительное время, и геморрагическим, происходящим вследствие разрыва сосудов с излиянием крови в окружающее пространство. Оба состояния смертельно опасны и требуют срочной медицинской помощи. Первые часы после приступа решающие!

\section{Главные причины инсульта:}

- гиподинамия: отсутствие двигательной активности вызывает системные поражения организма;

- эндокринные заболевания: нередко приводят к увеличенной выработке тромбоцитов, избыточному сгущению крови;

- ожирение: платформа для развития многих нарушений сердечнососудистой системы и обмена веществ;

- хроническая гипертония: из-за повышенной нагрузки сосуды быстро изнашиваются, становятся хрупкими;

- атеросклероз: просвет артерий постепенно снижается из-за отложений в них бляшек; 
- генетическая предрасположенность: слабая сосудистая система некоторым достается в наследство.

У молодых людей к инсульту приводят обычно врожденные поражения сосудов головного мозга, последствия черепных травм, некоторые системные заболевания, в том числе тяжелая степень гипертонии.

Алкоголь и курение табака также планомерно приводят к сосудистым нарушениям: разрушают их структуру, увеличивают проницаемость, снижают тонус и эластичность. Данные привычки опасны для мужчин и женщин любого возраста.

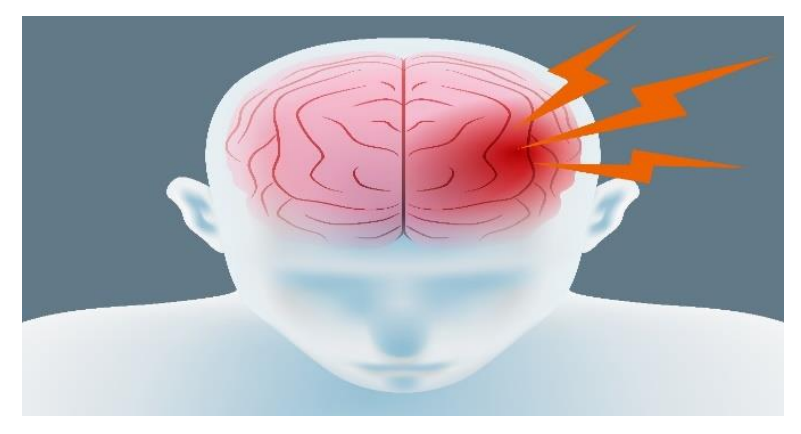

\section{Предвестники и симптомы инсульта:}

За несколько дней до развития инсульта вероятны следующие странные ощущения:

* внезапная сонливость в дневное время при нормальном режиме отдыха;

* спонтанные приступы тахикардии или замедление частоты сокращений сердца;

* резкое головокружение при отсутствии активных движений и перемен положения тела;

кровотечение из носа без причины.

Распространенные симптомы развивающегося инсульта:

* приступ нестерпимой головной боли;

* зрительные нарушения: изменение цветовосприятия, пятна и затемненные участки перед глазами, двоение, мелькание «мошек», сужение поля зрения;

* изменение координации движений и мимики: неспособность нормально ходить, жестикулировать, паралич лицевых мышц с одной стороны, онемение конечностей; 


\section{ЦИФРОВИЗАЦИЯ КАК НОВАЯ ПАРАДИГМА РАЗВИТИЯ: ВЫЗОВЫ, ВОЗМОЖНОСТИ И ПЕРСПЕКТИВЫ}

* вероятна также резкая тошнота, спазмы в брюшной полости или однократная рвота.

\section{Как определить начавшийся инсульт:}

Больному нужно симметрично вытянуть вперед обе руки, затем поочередно каждой ладонью коснуться своего носа. Неспособность сделать это, резкие нарушения траектории движений, перекошенное тело - признаки приступа.

Глядя в зеркало или на собеседника следует широко улыбнуться, далеко высунуть язык, произнести несколько слов. О возможном инсульте сигнализируют перекошенные или парализованные уголки рта, отклонения языка в сторону, невнятная речь.

Необходимо попытаться написать на бумаге или набрать на клавиатуре любой текст. При инсульте сделать это очень тяжело, получается бессмысленный набор букв.

Один или несколько тревожных симптомов - повод срочно вызывать медицинскую помощь или ехать в больницу. Первые 3 часа после инсульта наиболее важны для восстановления циркуляции крови и предотвращения необратимых поражений мозга. Врач необходим и в случаях, когда самочувствие восстановилось самостоятельно.

\section{Первая помощь при инсульте:}

Усадить или помочь лечь больному в удобное положение, под голову положить подушку, валик из одежды или полотенца.

Расстегнуть ремни, ослабить воротник, завязки, расстегнуть пуговицы на шее и груди, освободив дыхание.

Обеспечить приток свежего воздуха, открыв в помещении дверь и окна.

Измерить пострадавшему артериальное давление и пульс.

При отсутствии самостоятельного дыхания и сознания разрешено выполнить непрямой массаж сердца, ритмично нажимая на грудную клетку. Но лишь при наличии необходимых навыков.

\section{Реабилитация после инсульта:}

Реанимационные процедуры больной проходит в стационаре. После нормализации кровообращения и стабилизации физического состояния необходимо восстановление утраченных навыков. Нарушения, возможные после инсульта:

- потеря подвижности отдельных частей тела;

- невнятная речь; 
- изменение психического, интеллектуального, эмоционального состояния.

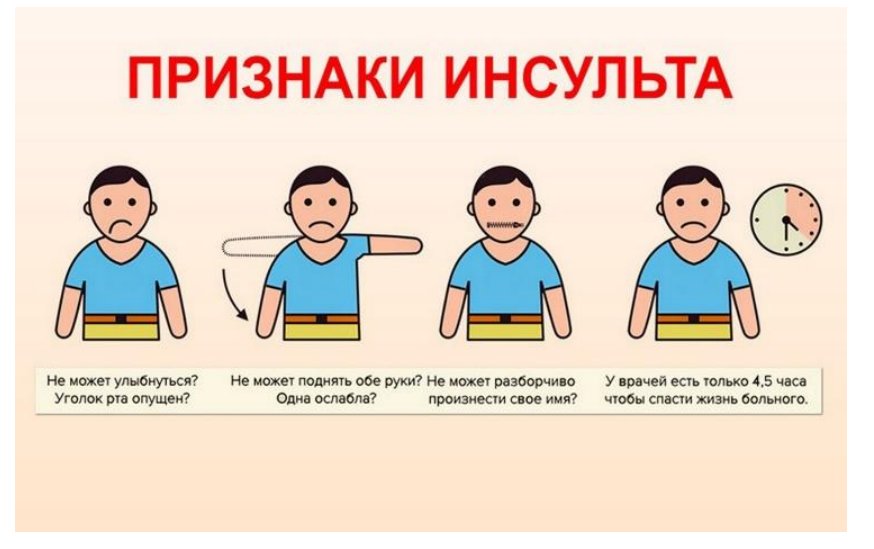

Рис. 2. Брошюра

\section{Список литературы}

1. Актуальные вопросы клинической диагностики внутригоспитального ишемического инсульта / С.В. Коломенцев., И.А. Вознюк, М.М. Одинак и др. // Вестн. Рос. воен.-мед. акад. - 2017. - № 3 (59). - С. 98-104.

2. Воскобойникова, И.П. Реабилитация больных, перенесших инсульт / И.П. Воскобойникова // Главврач. - 2018. - № 5. - С. 9-19.

3. Восстановление двигательных функций в раннем восстановительном периоде геморрагического инсульта: возможности хирургического и консервативного лечения / Л.Р.Курилина, Е.В. Дьякова, А.Ф. Рехалов и др. // Мед. альманах. - 2016. - № 5 (45). - С. 119-122.

4. Гольдблат, Ю.В. Основы реабилитации неврологических больных / Ю.В. Гольдблат. - СанктПетербург : СпецЛит, 2017. - 767 с.

5. Гусев Е.И., Скворцова В.И. Ишемия головного мозга. М., 2005. 327с.

6. Диагностика и лечение когнитивных нарушений после инсульта / В.В. Захаров, Н.В. Вахнина, Д.О. Громова и др. // Мед. совет. - 2015. - № 10. C. 14-21.

7. Дифференциальная диагностика инсульта на догоспитальном этапе / М.А. Милосердов, Н.Н. Маслова, Ю.С. Корнева, О.О. Фролкова // Скорая мед. помощь. - 2015. - № 3. - С. 25-30.

8. Дробышев, В. Фармакопунктура биорегуляционных препаратов в раннем восстановительном периоде ишемического инсульта / В. Дробышев // Врач. - 2018. - № 6. - С. 87-88. 
9. Мильнер, Е.Г. Формула жизни. - М.: Физкультура и спорт, - 2011. $326 \mathrm{c}$.

10. Основы медицинских знаний и здорового образа жизни: Учебное пособие: Р.И. Айзман, В.Б. Рубанович, М.А. Суботялов: Издательство: Сибирское университетское издательство, - 2010. - 98 с.

11. Толкачев, Б.С. Физкультурный заслон ОРЗ. - М., - 2018. - С. 102. 